\title{
Synthetic $P$ wave seismograms from Longshot, Milrow and Cannikin explosions
}

\begin{abstract}
A R BANGHAR
Neutron Phys $\times$ Division. Bhabha Atomic Research Centre, Trombay. Bombay 400 085. India

MS received 29 No. : mber 1982; revised I March 1983

Abstract. The effect of spalling anc other transfer functions is considered on the amplitude spectra and waveforms of telese $\mathrm{m}$. . Short period $P$ wave seismograms generated due to Longshot, Milrow and Cannikin unde z ground nuclear explosions. Source models of Haskell and Seggern were used for computing , wave sei nogi, me from these events. Step-by sep variations of the amplitude spectra and waveforms of $P$ wave signal as .. propagates from source to various seismometer array stations show that the source function, the source crust transfer function. the mantle transfer function and the spalling function are the most important factors that influence shaping of spectra and waveforms of $P$ seismograms. Comparison of computed and observed $P$ wave seismograms at various seismometer array stations for Longshot explosion shows that computed seismograms do reproduce many of the features of observed seismograms. The results also support the conclusion that overburden $P$ wave velocity inferred from observed seismograms is less as compared to its value obtained from on-site measurements.
\end{abstract}

Keywords. Seismograms; signal; underground nuclear explosions; earthquakes: waveforms; reduced displacement potential; source function; source crust; receiver crust; anelasticity: yield; composite transfer function; source depth.

\section{Introduction}

Vanous investigators have reported differences in the amplitude spectra of $P$ waves from underground nuclear explosions and earthquakes having nearly same body wave magnitudes and from same tectonic regions (Wyss et al 1971; Bakun and Johnson 1971; Molnar 1971; Hasegawa 1972, 1973). Some investigators have attributed spectral differences from explosions and earthquakes to the differences in source dimensions of explosions and earthquakes (Carpenterand Thirlaway 1966; Liebermann and Pomeroy 1969, 1970), while others attributed these differences to source dimensions as well as the source time functions (Wyss et al 1971; Hasegawa 1972. 1973; McEvilly and Peppin 1972). On the other hand, Tsai and Aki (1971) and Helmberger and Harkrider (1972) pointed out that spectral differences between underground nuclear explosions and earthquakes can be explained by focal depth effect itself.

For earthquakes, the source time function is usually considered to be a step (Ben-Menahem 1967; Tsai and Aki 1970) or approximately a step with a finite rise time (Ben-Menahem and Toksoz 1963). However, at present, there is no complete agreement among different investigators about the shape of the reduced displacement potential of underground nuclear explosions (Aki et al 1974; Murphy 1977) and many assumptions are made in the literature (Muller 1973). Banghar (1980a, 1981) showed that delta and heaviside types of reduced displacement potentials are not suitable as a source function for underground nuclear explosions, because these functions do not predict the increase in period of $P$ wave seismograms with the increase in yield. Kogeus 
(1968) synthesized teleseismic short period $P$ wave seismograms for underground explosions, using numerical values of reduced displacement given by Werth and Herbst (1963) and Holzer (1966). Haskell (1967) presented analytic expression for reduced displacement potential and the same was employed by Hasegawa (1971, 1972. 1973 ) and Douglas et $a l$ (1972) for computing $P$ and Rayleigh waves seismograms. Seggern and Blandford (1972) presented alternate analytic expression for reduced displacement potential. This expression was used only recently (Burdick and Helberger 1979) for computing teleseismic body waves. However, synthetic seismograms were not compared for Haskell and Seggern source models. Hence, it is desirable to compute and compare short period $P$ seismograms for both of these models.

Several explanations were proposed to explain the long duration of $P$ wave coda in seismograms (because explosion is relatively a short-time phenomenon) from explosive source. One of the possible explanations for long duration of $P$ waves from nuclear explosions is spall-closure (Frasier 1972: Springer 1974), and spalling is observed for many underground explosions. Although several investigators have synthesized $P$ wave seismograms for underground nuclear explosions, a majority of them have not considered the spalling effect (Nair 1977). Hence, it is pertinent to compute $P$ wave seismograms for various shapes of reduced displacement potential for underground explosions, while taking into account the effect of spalling.

\section{Theory}

We wish to compare the synthesized and recorded short period $P$ wave seismograms from underground nuclear explosions at Eskadalemuir (EKA), Gauribidanur (GBA), Warramunga (WRA) and Yellowknife (YKA) seismometer array stations. Seismogram can be viewed as the final output of a sequence of filters arranged in a cascade. the input to which is the signal generated at the source. Hence, in order to compute seismograms, it is essential to know the transfer functions (impulse responses) of various filters which constitute earth-seismometer system together with the transfer function (impulse response) of source function. The theories of transfer functions of the constituents of the model needed for synthesizing $P$ wave seismograms have been reported earlier by their respective originators (Banghar 1980a). Therefore, only final forms of transfer functions are presented here.

\subsection{Source function}

Source function for Haskell's formulation of reduced displacement potential is represented as (Banghar 1980a)

$$
u(R, \omega)=\frac{\psi(\infty)}{\alpha R}\left[\frac{1+24 B}{[1+i(\omega / k)]^{4}}-\frac{24 B}{[1+i(\omega / k)]^{5}}\right]
$$

where $\psi(\infty)$ is the value of $\psi$ at large times, $R$ is the radial distance, $\alpha$ is the compressional velocity of the medium in which explosion is detonated and $\omega$ is the angular frequency. $B$ and $k$ are constants. Numerical values of $B$ and $k$ (Haskell 1967) are available for five kiloton explosions detonated in four geological media, however, source function can be computed for any yield using scaling laws (Banghar 1980a). This expression is subsequently referred to as Haskell model in this paper. Equation (1) shows that far-field displacement spectra behaves as $\omega^{-4}$ at high frequencies. This fall-off indicates a high frequency scaling of displacement spectrum inversely proportional to the cube root of yield (Seggern and Lambert 1970). This frequency scaling of displacement spectrum at high frequencies seems to be unrealistic (Aki et al 1974). 
In order to avoid $\omega^{-4}$ dependence of displacement spectra at high frequencies, Seggern and Blandford (1972) presented alternate analytic expression for reduced displacement potential. Using analytic expression for reduced displacement potential of Seggern and Blandford (1972), it can be shown (Banghar 1980a, 1981) that

$$
u(R, \omega)=\frac{\psi(\infty)}{\alpha R}\left[\frac{1+2 B}{[1+i(\omega / k)]^{2}}-\frac{2 B}{[1+i(\omega / k)]^{3}}\right]
$$

The meaning of various symbols in (2) a re same as in (1); however, the values of $B$ and $k$ in (2) are different from their values in (I). Numerical values of $B$ and $k$ in (2) for five kiloton explosions in four different geological media are given by Banghar (1980a). Source function represented by (2) is referred to as the Seggern model in this paper.

\subsection{Source crust transfer function}

For an underground explosion, the source crust transfer function is represented by (Fuchs 1966; Banghar 1980a, 1981)

$$
T(\omega)=2 i \rho_{n} \alpha_{n}^{2} \sin i_{n}^{s} \cos i_{n}^{s}\left[\bar{\Delta}_{H}-\frac{\bar{\Delta}_{V}^{\prime}}{k}\right]
$$

where $\rho_{n}, a_{n}$ and $i_{n}^{s}$ are respectively the density, $P$ wave velocity and angle of incidence of $P$ waves into mantle in source region, $k$ is the horizontal component of wave number, and is related to the apparent velocity $c$ by a relation $\omega=c k, \vec{\Delta}_{H}$ and $\bar{\Delta}_{V}$ represent the $P$ wave contributions for the horizontal and vertical point forces.

\subsection{Mantle transfer function}

The effect of mantle on seismic waves that propagate through it can be accounted for by two factors. One of these factors represents the effect due to anelasticity of the mantle and is described in this section. The second factor representing the variation of the amplitude of seismic waves due to geometrical spreading is related to variation of velocity as a function of depth. This geometrical spreading factor is described separately subsequently.

The mantle is assumed to be homogeneous and anelastic. It is further assumed that absorption mechanism is linear and the quality factor $Q$ is independent of frequency. Following Futterman (1962) and Banghar (1982), the mantle transfer function can be represented as

$$
\begin{array}{r}
M(\omega)=\exp \omega\left[-\frac{T^{*}}{2}\left(1-\exp \left(-\omega / \omega_{0}\right)\right)+\right. \\
\left.i\left(T_{p}-\frac{T^{*}}{\pi} L_{n}\left(\gamma \omega / \omega_{0}\right)\right)\right]
\end{array}
$$

where $\omega_{0}$ is low cut-off angular frequency demanded by theory, and $L_{n} \gamma$ equals 0.5772157 . The $\omega_{0}$ value is not critical, provided it is not zero and is sufficiently lower than the lowest angular frequency taken into account (Kogeus 1968). It is generally taken to be $10^{-3} \mathrm{sec}^{-1}$. The parameter $T^{*}$ is defined by $T^{*}=T_{p} / Q$, where $T_{p}$ is the travel time of $P$ waves in the mantle. 


\subsection{Geometrical spreading factor}

This factor (GSF) is represented (Carpenter 1966) by

$$
\operatorname{GSF}=\alpha_{n}\left(\alpha_{n} \rho_{n} / \alpha_{n}^{0} \rho_{n}^{0}\right)^{1 / 2} G(\Delta)
$$

where

$$
G(\Delta)=\frac{1}{R_{e}^{2}}\left[\frac{1}{\sin \Delta} \frac{\mathrm{d} T_{p}}{\mathrm{~d} \Delta} \frac{\mathrm{d}^{2} T_{p}}{\mathrm{~d} \Delta^{2}}\right]^{1 / 2}
$$

and $\alpha_{n}^{0}, \rho_{n}^{0}$ are the $P$ wave velocity and density in the mantle (Douglas et al 1972) below the station. $R_{e}$ is the radius of the earth, $\Delta$ is the epicentral distance.

\subsection{Receiver crust transfer functions}

The crustal transfer functions for a plane $P$ wave incident from below on plane parallel layers were presented by Haskell (1953, 1962). In the notation of Banghar (1982), the horizontal $\left(U_{H}\right)$ and the vertical $\left(U_{V}\right)$ transfer functions of the receiver crust are

$$
\begin{aligned}
& U_{H}=2\left(J_{42}-J_{32}\right) / D \sin i_{n}^{R}, \\
& U_{V}=2\left(J_{41}-J_{31}\right) / D \sin i_{n}^{R},
\end{aligned}
$$

where

$$
D=\left(J_{11}-J_{21}\right)\left(J_{32}-J_{42}\right)-\left(J_{12}-J_{22}\right)\left(J_{31}-J_{41}\right)
$$

and $J_{11}, J_{12}$, etc. are the elements of crustal matrix $J . \mathrm{i}_{n}^{R}$ is the angle of incidence of $P$ waves at the base of crust in the region of receiver.

\subsection{Seismometer transfer function}

We wish to compute seismograms to be recorded by seismometer array stations of the United Kingdom Atomic Energy Authority (UKAEA). The recording systems of these stations are defined by number of zeros (at the origin) and poles (Mowat and Burch 1974). The transfer function $I(\omega)$ for these stations is represented (Banghar 1980a) as

$$
I(\omega)=z^{n} /\left(z-\gamma_{1}\right) \ldots\left(z-\gamma_{m}\right)
$$

where $z=i \omega, n$ is the number of zeros at the origin, and $\gamma_{1}, \gamma_{2}, \ldots \gamma_{m}$ are $m$ poles. The number of poles together with their locations and the number of zeros at origin (for seismometer-array stations of UKAEA) are given by Mowat and Burch (1974).

\subsection{Spalling function}

Spalling may be defined as the physical parting (Eisler and Chilton 1964) of the near surface layers originally in intimate contact. This parting takes place under the action of stress waves produced by the contained underground explosions (Rinehart 1960) in a particular range of yield and depth of emplacement (Eisler and Chilton 1964). Spalling has been observed for most underground explosions (King et al 1974). Hence, it is pertinent to consider the effect of spalling, while computing the seismograms. King et al (1974) proposed a model for spalling, according to which, spalling function $\mathrm{SP}(\omega)$ can be represented (Banghar 1980a) as 


$$
\mathrm{SP}(\omega)=\left[1+A^{\prime} \exp \left(-i \omega \tau^{\prime}\right)\right]
$$

where $A^{\prime}$ is the amplitude ratio of $P$ waves generated by slapdown to $P$ waves generated by underground nuclear explosions and $\tau^{\prime}$ is the time interval between the phases mentioned above.

\subsection{Composite transfer function}

The composite transfer function $F(\omega)$ of vertical component of $P$ wave signal can be obtained by multiplication of various transfer functions given in previous sections. This function is given below

$$
F(\omega)=u(R, \omega) * T(\omega) * M(\omega) * U_{V} * I(\omega) * \mathrm{SP}(\omega) * \mathrm{GSF}
$$

$P$ wave seismogram can be obtained by taking inverse Fourier transform of (12).

\section{Results and discussions}

Amplitude spectra and waveforms of teleseismic short period $P$ waves generated by underground nuclear explosions were computed as to be recorded by various seismometer array stations for source models of Haskell and Seggern. Influences of various parameters such as focal depth, yield variation, crustal structure variation at source, on the amplitude spectra and waveforms of $P$ waves were investigated. The resuits obtained from this study indicate that transfer functions of the source, the source crust, the mantle and spalling are the most predominant factors that influence the shaping of $P$ seismograms. Since the comparison between computed and recorded $P$ seismograms will provide information about the manner in which observed seismograms differ from computed ones, it is desirable to compute teleseismic $P$ seismograms for some known underground nuclear explosions. For this study, Longshot, Milrow and Cannikin underground nuclear explosions were chosen because of the following reasons: (i) crustal structure in the source region and detonation media are known, (ii) focal depths of these events are known precisely, (iii) their yields cover a wide range, (iv) slapdown parameters for these events are available, (v) easy availability of array data from UKAEA. Pertinent data relating to these events are given in table 1. Epicentral distances of these events are about $36.12^{\circ}, 77.61^{\circ}, 81.18^{\circ}$ and $85.66^{\circ}$ from YKA, EKA, WRA and GBA seismic array stations respectively. Crustal model in source region together with the crustal models at these seismometer array stations are given in table 2. Crustal model in source region is that of Orphal et al (1970) and Engdahl and Tarr (1970), whereas crustal models at EKA, GBA, WRA and YKA respectively are those of Parks (1967), Arora (1977), Barr (1971) and Cleary (1974).

The earth model used for the synthesis is that of Fuchs (1966). Explosive source is located within a layered crust whereas the receiver is at the free surface of layered crust. All the layers both in source and receiver regions are assumed to be horizontal. The angles of incidence used for computing the source and receiver crusts transfer functions are obtained from Banghar (1970). The crustal models used in these computations assume that the mantle is a uniform half space, whereas in actual calculations, the $P$ wave through the mantle is assumed to follow the standard travel time curve. Seggern and Lambert (1972) reported that the Amchitk $\varepsilon$ underground nuclear explosions follow the 'hard rock' magnitude scaling at Nevada test site. Hence, granite shot medium was used for computing source functions for these events 
Table 1. Underground nuclear explosion locations and other pertinent data.

\begin{tabular}{|c|c|c|c|}
\hline & Longshot & Milrow & Cannikin \\
\hline Location & $\begin{array}{r}51.42^{\circ} \mathrm{N} \\
179.18^{\circ} \mathrm{E}\end{array}$ & $\begin{array}{c}51.44^{\circ} \mathrm{N} \\
179.18^{\circ} \mathrm{E}\end{array}$ & $\begin{array}{r}51.5^{\circ} \mathrm{N} \\
179.1^{\circ} \mathrm{E}\end{array}$ \\
\hline Date & 29 Oct. 1965 & 2 Oct. 1969 & 6 Nov. 1971 \\
\hline Time & $\begin{array}{lll}21 & 00 & 00.08\end{array}$ & 220600.04 & $2200 \quad 00.62$ \\
\hline Yield (kiloton) & $=85$ & $=1000$ & $\leq 5000$ \\
\hline Depth $(\mathrm{km})$ & 0.702 & 1.218 & 1.791 \\
\hline Shot medium & Andesite/ Basalt & Pillow Lava & Pillow Lava \\
\hline Magnitude $M_{S} / m_{b}$ & $3.9 / 6.1$ & $4.9 / 6.5$ & $5.7 / 6.8$ \\
\hline $\begin{array}{l}\text { Time interval between } \\
\text { slapdown and } P(\mathrm{sec})\end{array}$ & $0.87 \pm 0.03$ & $1.35 \pm 0.6$ & $1.85 \pm 0.08$ \\
\hline $\begin{array}{l}\text { Slapdown amplitude } \\
\text { relative to } P \text { amplitude }\end{array}$ & $0.3 \pm 0.1$ & $0.5 \pm 0.1$ & $0.4 \pm 0.1$ \\
\hline
\end{tabular}

For computing various transfer functions (impulse responses) needed for synthesizing $P$ seismograms, a computer program was developed for BESM-6 computer at the Bhabha Atomic Research Centre. Bombay. For purposes of modelling and comparison with observed data, a time-domain description of wave propagation is more advantageous than frequency domain. Therefore, step-by-step variations of the amplitude spectra and waveforms of $P$ waves are shown. For each of these source models. shaping of the amplitude spectra and waveforms of $P$ waves (vertical component). as signal propagates from source to receiver at GBA are presented in figures 1 to 3 for Longshot, in figures 4 to 6 for Milrow and in figures 7 to 9 for Cannikin underground nuclear explosions. The discussion of the variations in the amplitude spectra and waveforms of signal is arranged as a function of yield.

It is relevant to discuss some of the transfer functions. For Longshot explosion, maxima and minima in the amplitude (trace 2 in figure 1) are due to the constructive and destructive interference between the direct, reflected and converted phases. Low frequency riding over high frequency amplitude is due to constructive and destructive interference between $P, p P$ and higher order reflected and converted phases. This figure (trace 2) shows that amplitude falls with decreasing frequency from say $1 \mathrm{cps,}$ the first minimum being in the vicinity of $0 \mathrm{cps}$. The second theoretical minimum in the amplitude spectrum occurs at about $3 \mathrm{cps}$ and is due to destructive interference between $P$ and $p P$ phases. This result shows that the minimum in the amplitude spectra of $P$, and $P c P$ phases of Longshot underground nuclear explosion at about $1 \mathrm{cps}$ obtained by Buchbinder (1968) is probably not due to the effect of focal depth (Hasegawa 1972). Impulse response of this function shows a distinct $p P$ phase (trace 2 ' in figure 1). Comparison of trace 2 in figures 1,4 and 7 shows that the fundamental frequency of the amplitude spectrum decreases with increase in focal depth. It may also be seen from these figures (traces $2^{\prime}$ ) that $p P$ phase is more distinct for Cannikin explosion as compared to Longshot explosion. The impulse response of spalling function is composed of two pulses (traces 6 ' in figures 1,4 and 7 ). This result indicates 
Table 2. Crustal models used in computations of seismograms.

\begin{tabular}{lcccc}
\hline Layer & $\begin{array}{c}P \text {-wave } \\
\text { Thickness } \\
(\mathrm{km})\end{array}$ & $\begin{array}{c}S \text {-wave } \\
\text { velocity } \\
(\mathrm{km} / \mathrm{sec})\end{array}$ & $\begin{array}{c}\text { velocity } \\
(\mathrm{km} / \mathrm{sec})\end{array}$ & $\begin{array}{c}\text { Density } \\
\left(\mathrm{g} / \mathrm{cm}^{3}\right)\end{array}$ \\
\hline
\end{tabular}

(a) Structure at source for Longshot, Milrow and Cannikin explosions

$\begin{array}{lcccc}1 . & 0.30 & 4.06 & 1.93 & 2.35 \\ 2 . & 0.03 & 3.34 & 1.62 & 2.26 \\ 3 & 0.16 & 4.06 & 1.93 & 2.35 \\ 4 . & 0.01 & 3.33 & 1.62 & 2.26 \\ 5 . & 0.26 & 4.06 & 1.93 & 2.35 \\ 6 . & 0.04 & 4.61 & 2.23 & 2.47 \\ 7 . & 0.03 & 4.06 & 1.93 & 2.35 \\ 8 . & 0.14 & 4.61 & 2.23 & 2.47 \\ 9 . & 0.13 & 4.06 & 1.93 & 2.35 \\ 10 . & 0.18 & 4.83 & 2.28 & 2.13 \\ 11 . & 0.32 & 4.87 & 2.32 & 2.35 \\ 12 . & 10 & 5.5 & 3.20 & 2.70 \\ 13 . & 30 & 6.6 & 3.80 & 3.00 \\ \text { Mantle } & & 8.1 & 4.70 & 3.30\end{array}$

(b) Siructure at Eskadelemuir (Scolland)

$\begin{array}{lrlll}1 . & 5.3 & 6.14 & 3.55^{*} & 2.80 \\ 2 . & 19.7 & 7.28 & 4.20^{*} & 3.20 \\ \text { Mantle } & & 8.09 & 4.67 & 3.38\end{array}$

(c) Structure at Gouribidanur (India)

$\begin{array}{lllll}1 . & 8.7 & 5.62 & 3.28 & 2.70 \\ 2 . & 10.5 & 6.07 & 3.51 & 2.80 \\ 3 . & 17.2 & 6.50 & 3.95 & 3.00 \\ \text { Mantle } & \infty & 7.98 & 4.62 & 3.33\end{array}$

(d) Structure at Warramunga (Australia)

$\begin{array}{lcccc}1 . & 20.00 & 6.20 & 3.58^{*} & 2.70 \\ 2 . & 19.5 & 6.50 & 3.75^{*} & 2.90 \\ \text { Mantle } & \infty & 8.10 & 4.70^{*} & 3.30\end{array}$

(c) Structure at Yellon'knife (Canada)

\begin{tabular}{lcccc}
1. & 1.5 & 5.64 & 3.25 & 2.67 \\
2. & 32.5 & 6.04 & 3.69 & 2.71 \\
Mantle & $\infty$ & 8.15 & 4.71 & 3.32 \\
\hline
\end{tabular}

\footnotetext{
* In those regions where $S$-wave velocities are not reported. these are deter-
} mined from the relation $\alpha^{2}=3 \beta^{2}$ for numerical computations.

that spalling can be considered as a secondary source similar to explosive source (Springer 1974). Comparison of traces 1 in figures 2 and 3 shows that the maximum amplitude of the source function occurs at a higher frequency for Haskell's model as compared to Seggern's model. The duration of impulse response (traces 1' in figures 2 and 3) is longer for the source model of Seggern as compared to that of Haskell. Traces $a$ (figures 2 and 3 ) show that beyond about $2.7 \mathrm{cps}$ the amplitude is nearly negligible for 

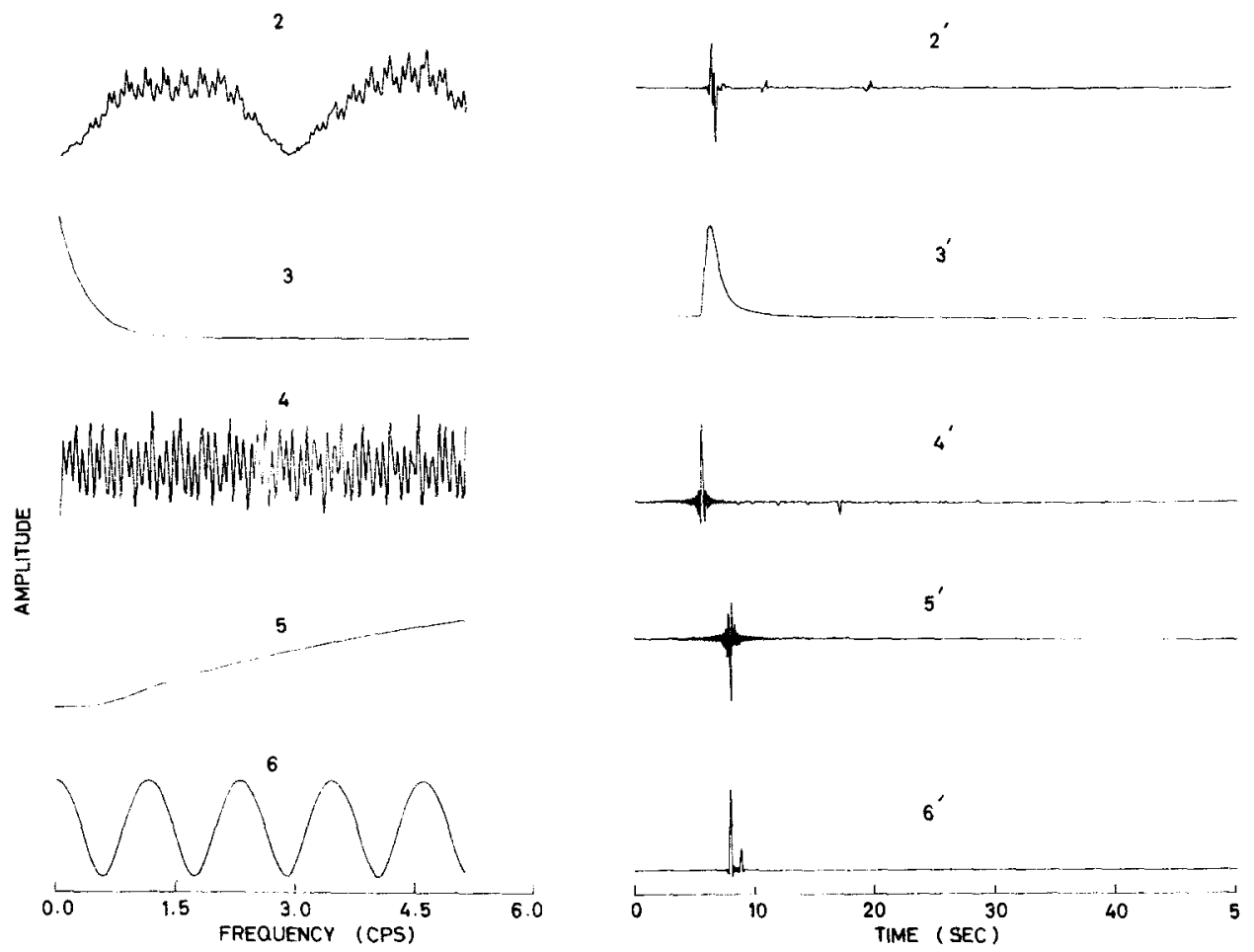

Figure 1. shows the amplitude spectra and impulse responses (arbitrary units) of the transfer functions that remain unchanged while computing variations in theoretical amplitude spectra and waveforms for Longshot as $P$ wave signal propagates from source (Amchitka Island) to Gauribidanur (GBA). India. Procedure for numbering traces in this figure is as follows: Traces 2 and 2 ' represent amplitude spectrum and impulse response of the source crust transfer function. Corresponding quantities for the mantle transfer function. the receiver crust transfer function. the recording system transfer function, and the spalling function are given by traces 3 and $3^{\prime}, 4$ and $4^{\prime}, 5$ and $5^{\prime}$. and 6 and $6^{\prime}$ respectively.

both the source models. Moreover, the second minimum in the amplitude spectrum of signal occurs at a frequency at which it occurs in the amplitude spectrum of source crust transfer function (traces 2 and $a$ in figures 1, 2 and 3). However, the first maximum in the amplitude spectrum of signal occurs at about $1.2 \mathrm{cps}$ (traces $a$ in figures 2 and 3 ), whereas the first maximum in the amplitude spectrum of source crust transfer function occurs at about $1.4 \mathrm{cps}$ (traces 2 in figure 1). This observation suggests that the fall-off in the amplitude spectra of underground nuclear explosions at low frequencies can be attributed both to the source and source crust transfer functions. For both these models, amplitude spectra are very similar. Examination of traces $a^{\prime}$ in these figures shows that $p P$ (this phase is quite distinct in the impulse response of the source crust transfer function) and $P$ phases are completely merged. Attenuation in the mantle is incorporated by assuming $T^{*}$ equals unity. This assumption seems to be reasonable (Carpenter and Flinn 1965) in the case of teleseismic short 

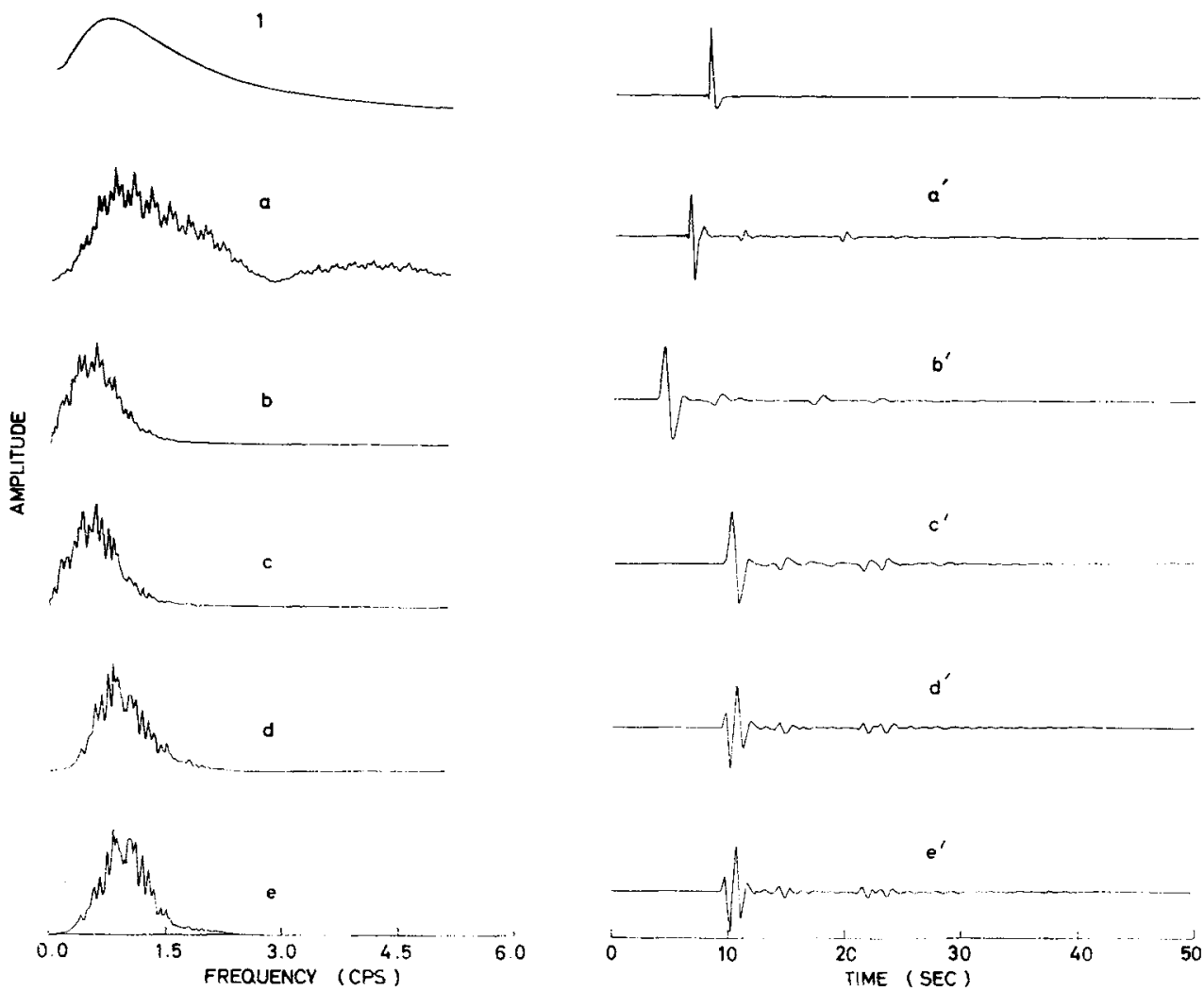

Figure 2. shows the step-by-step lariations in the amplitude spectrum and wateform of signal as it propagates from source to (BBA. The source model is that of Haskell. Traces 1 and 1 ' show the amplitude spectrum and impulse response of the source function. The amplitude spectra and waveforms of the signal at the base of crust in source and receiver regions are shown respectively by traces $a$, $a^{\prime}$ and $b$ and $b^{\prime}$. Thu amplitude spectrum and waveform at the top of crust in receiver region are given $h y$ traces $c$ and $c^{\prime}$ respectively. Traces $d$ and $d^{\prime}$ and $e$ and $e^{\prime}$ show respectively the amplitude spect ra and waveforms of computed signal without and with the effect of spalling.

period $P$ waves. This value of $T^{*}$ corresponds to the effective $Q$ value of the order of about 760. It is interesting that the amplitude spectrum is nearly negligible for frequencies greater than about $1.6 \mathrm{cps}$ (traces $b$ in figures 2 and 3 ), whereas the waveform duration is longer after passing through mantle as compared to its duration prior to its passage through it. The shapes of the amplitude spectra and waveforms of signal for Haskell and Seggern source models are nearly similar. However, the duration of signal (traces $b^{\prime}$ in figures 2 and 3 ) for the Seggern model is slightly more than its duration for Haskell model. Comparison of traces $b^{\prime}$ and $c^{\prime}$ in these figures shows that the effect of crustal structure in receiver region on $P$ wave seismogram is nearly negligible. Due to the effect of short period recording system on the signal, the 

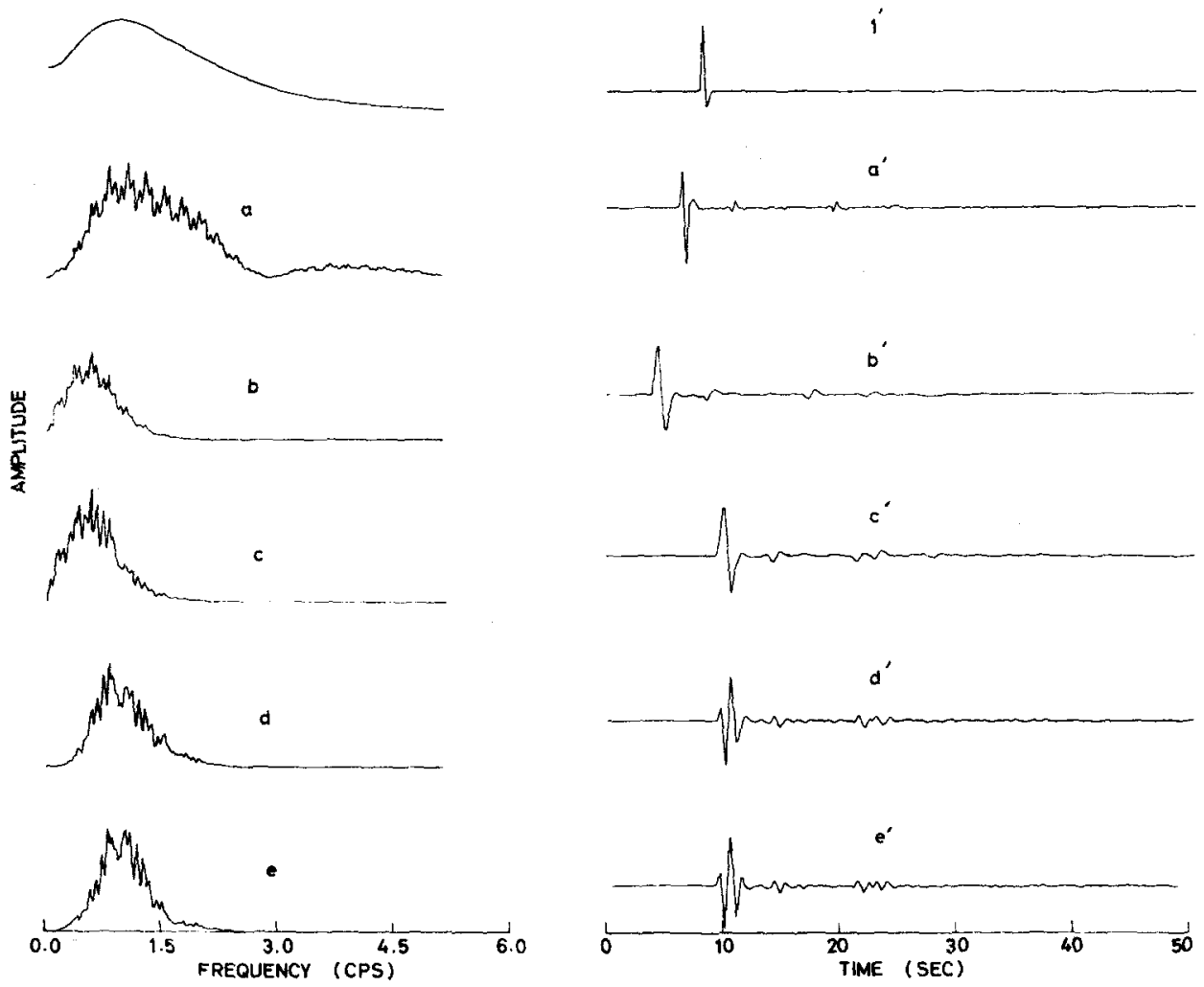

Figure 3. Amplitude spectrum and waveform as signal propagates from source to c;BA. The source model is that of Seggern. Symbols same as in figure 2 .

peak in the amplitude spectrum is shifted to higher frequency (compare traces, and $d$ ). Another important feature of the amplitude spectra (traces $d$ in figures 2 and 3) is their fall-off with decreasing frequency from, say about $0.8 \mathrm{cps}$. The amplitude spectra of $P$ waves from Longshot at YKA also indicated the fall-off in the amplitude spectrum with decreasing frequency for frequencies less than the frequency mentioned above. which was attributed to the combined effect of source function and focal depth by Hasegawa (1972). In order to show the effect of spalling distinctly, its influence was incorporated at this stage. The composite amplitude spectra and seismograms of $P$ waves are shown by traces $e$ and $e^{\prime}$ in these figures. It may be noted that the amplitude between 0.9 and $1.2 \mathrm{cps}$ is slightly amplified (compare traces $d$ and $e$ ) and the duration of seismogram is elongated due to the effect of spalling (compare traces $d^{\prime}$ and $e^{\prime}$ ). 

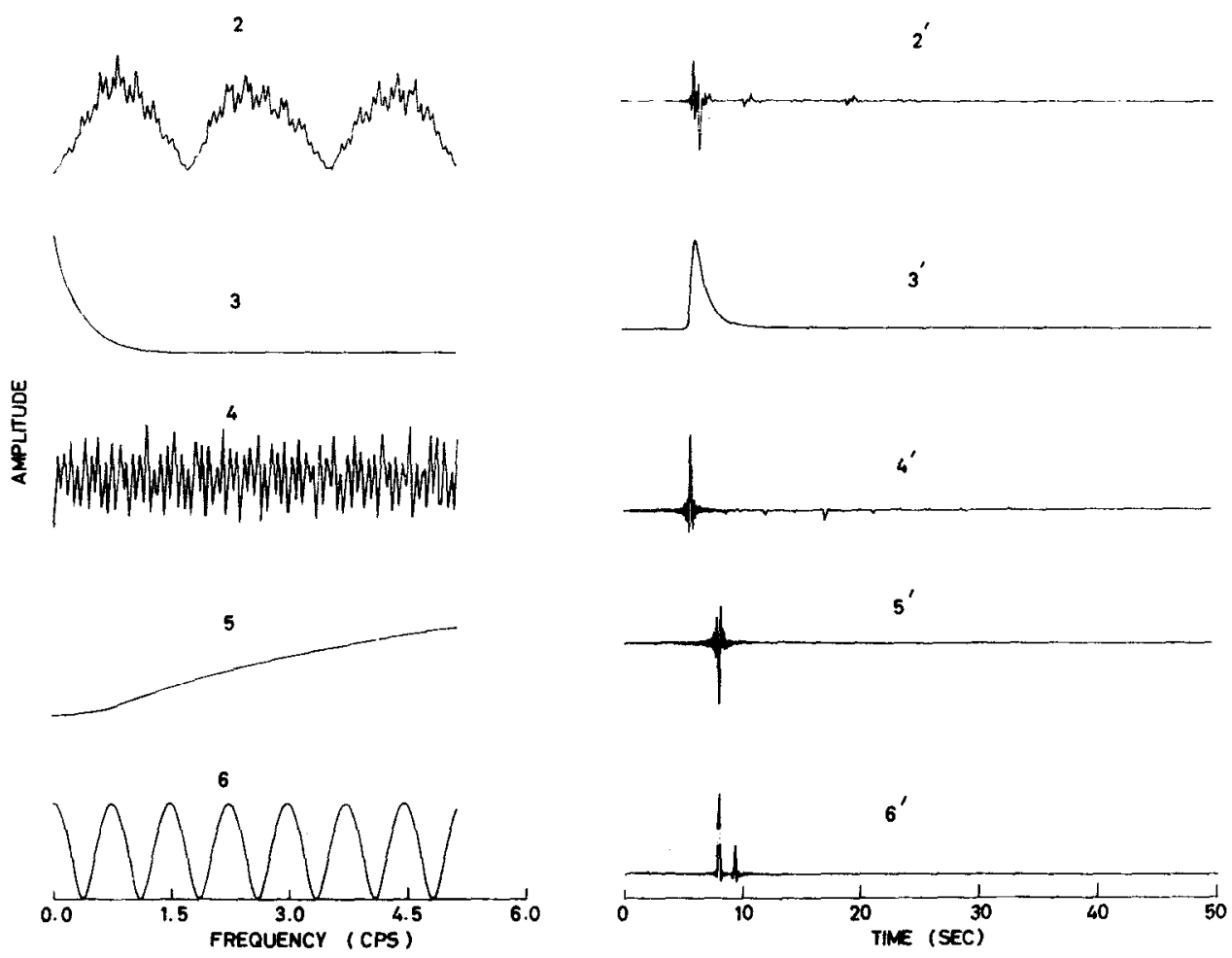

Figure 4. shows the amplitude spectra and impulse responses of the transfer functions that were held constant while computing the variations in the amplitude spectrum and waveform for Milrow as signal propagates from source to GBA. Symbols same as in figure 1.

Figures 5 and 6 show the shaping of the amplitude spectra and waveforms of signal for Milrow underground explosion. It can be seen (traces 1 and $l^{\prime}$ in figures 2, 3.5.6.8 and 9 that for a given source model. the amplitude peak shifts to lower frequency and the duration of impulse response increases, with increase in yield. It is interesting to note that for both models, the maximum in the amplitude spectrum of signal at the base of crust (traces $a$ in figures 5 and 6 ) occurs nearly at the same frequency and this frequency lies between the frequencies at which the maximum amplitude in the source function and the first maximum amplitude in the source crust transfer function occurs. This result again shows that the frequency at which the maximum occurs in the amplitude spectrum of signal at the base of crust in the source region. is prima rily governed both by source and source crust transfer functions. Comparison of traces $d^{\prime}$ and $e^{\prime}$ shows that the duration of signal is increased due to spalling. It may be noted that the amplitudes of $P$ seismogram for first three half cycles are not affected much due to spalling, whereas the amplitudes of fourth and fifth half cycles are more for seismograms which are computed while considering the effect of slapdown as compared to seismograms computed without taking account of slapdown. 

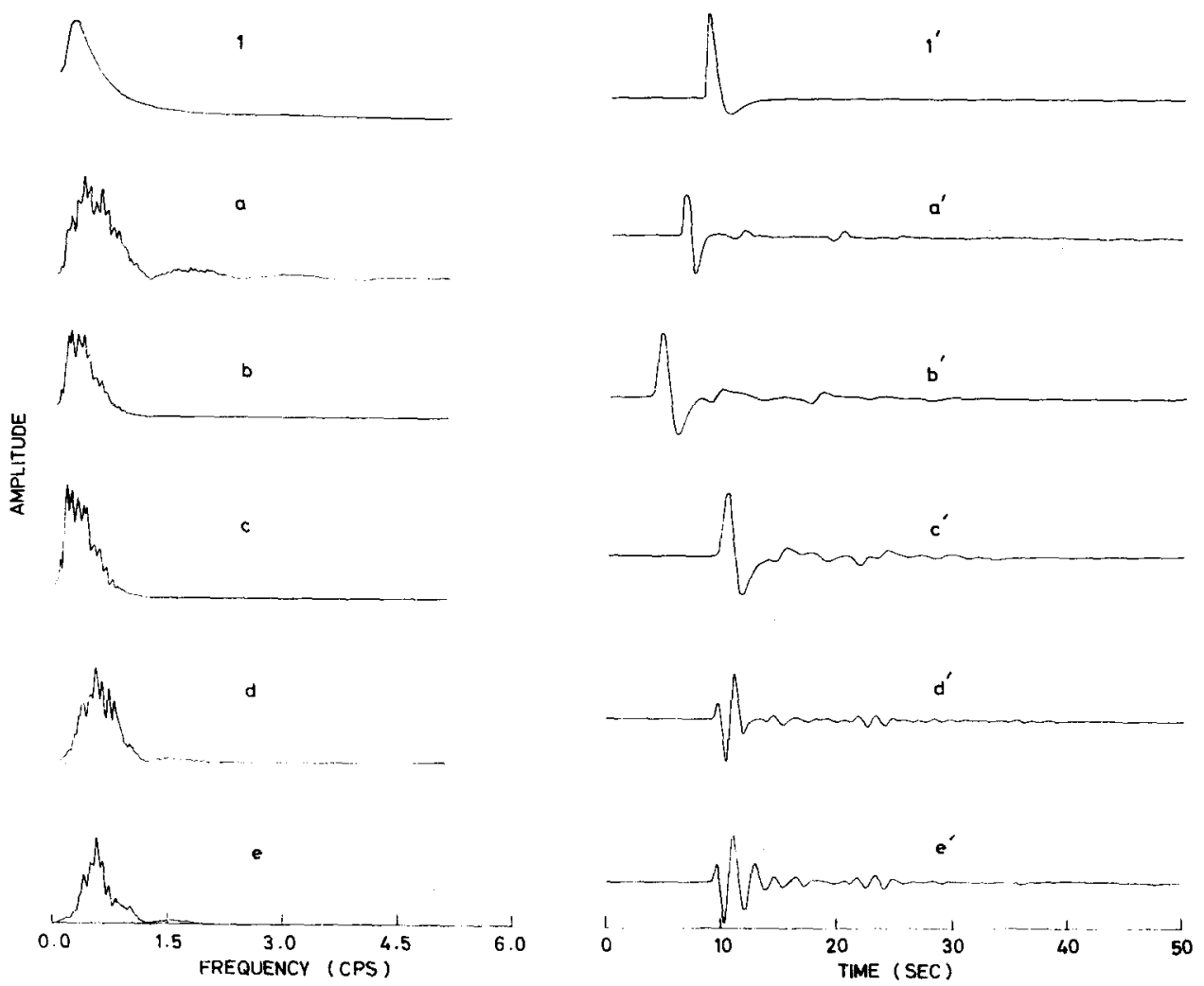

Figure 5. Amplitude spectrum and waveform for Milrow as signal propagates from source to GBA. Source model is that of Haskell. Symbols same as in figure 2.

The amplitude spectrum of signal for Cannikin explosion at the base of crust in source region (traces $a$ in figures 8 and 9) for these two source models shows some interesting features. One of these is that the second and third minima are recognizable in the amplitude spectrum for Seggern's model, whereas this is not the case in Haskell's model. Hence for large yields, high frequencies do get transmitted through source crust for Seggern's source model. In this case also, the duration of $P$ seismograms (compare traces $d^{\prime}$ and $e^{\prime}$ in figures 8 and 9 ) is increased due to the spalling effect.

For a given source model, comparison of composite $P$ seismograms for Longshot, Milrow and Cannikin underground nuclear explosions, shows that peak-to-peak amplitude and period of $P$ waves increase with increase in yield (Banghar 1980b). It is seen that peak frequency in the amplitude spectra is governed by the source function. the source crust transfer function and anelasticity of the mantle. It is also noticed that for a given explosion, pulse shapes of synthesized $P$ wave seismograms are almost equivalent for all practical purposes both for source models of Haskell and Seggern. Similarity of composite spectra for these models is mainly due to the dominant effect of the anelasticity of the mantle. 

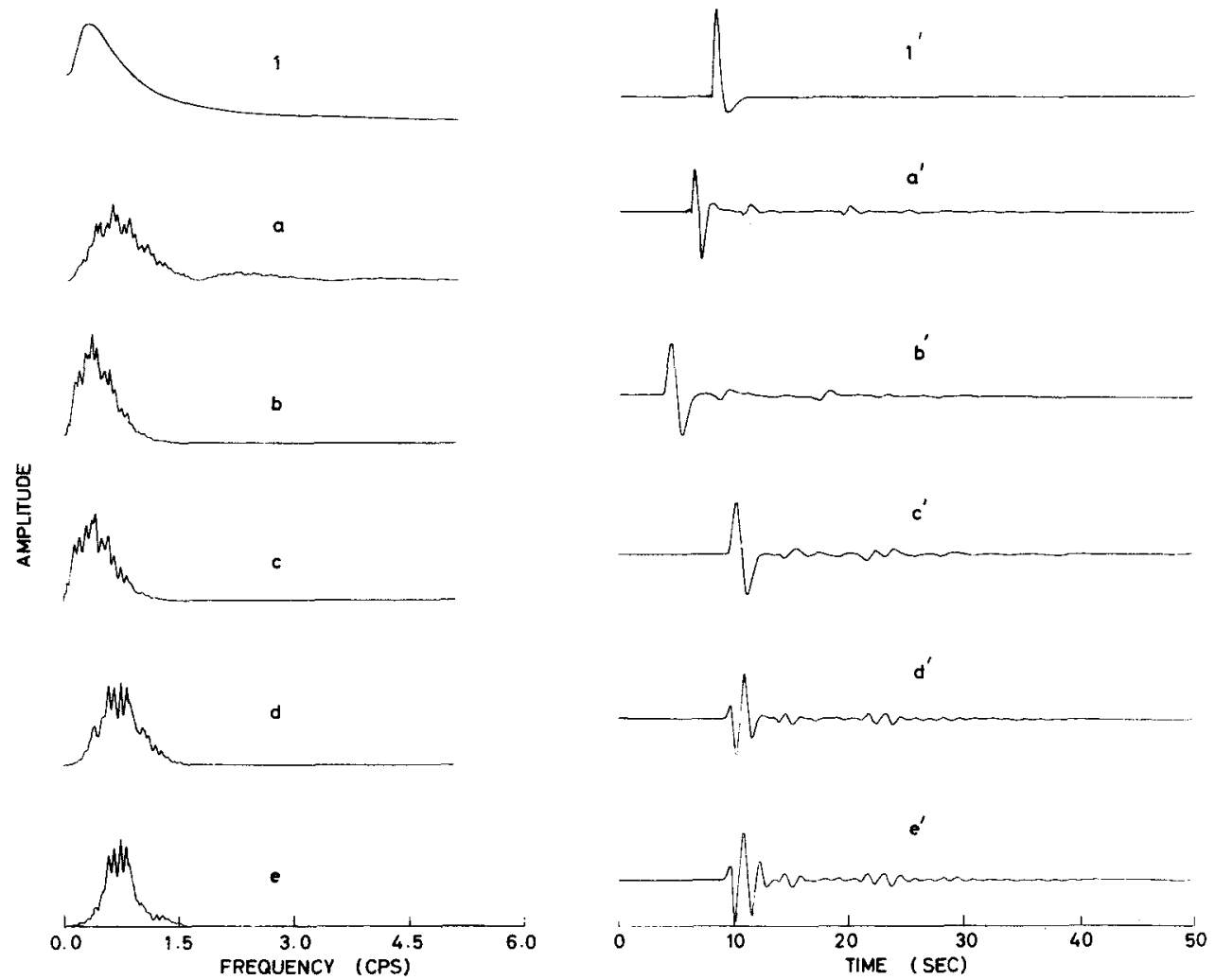

Figure 6. Amplitude spectrum and waveform for Milrow as signal propagates from source to GBA. Source model is that of Seggern. Symbols same as in figure 2.

Theoretical amplitude spectra and waveforms of signal as it propagates from source to receivers at YKA, WRA and YKA were also computed for these events for both the source models. It is noticed that shaping of the amplitude spectra and waveforms at these seismic array stations is almost similar to that at GBA. It is desirable to compare the synthesized and recorded $P$ wave seismograms at various seismometer array stations. Computed and observed $P$ seismograms are compared at FKA, GBA, WRA and YKA in figure 10 for Longshot explosion only because $P$ wave seismograms for Milrow and Cannikin explosions were saturated at these stations. It may be noted (traces $a_{1}$ and $b_{1}$ in figure 10 ) that the duration of seismogram is slightly elongated due to spalling. Comparison of traces $h_{1}$ and $c_{1}$ in figure 10 indicates that computed seismograms reproduce many of the features of observed seismograms. However, the agreement between the coda of computed and observed $P$ wave seismograms is much less satisfactory which may be due to the effect of scattering in the source region. inhomogeneities in the upper mantle and multipathing. 

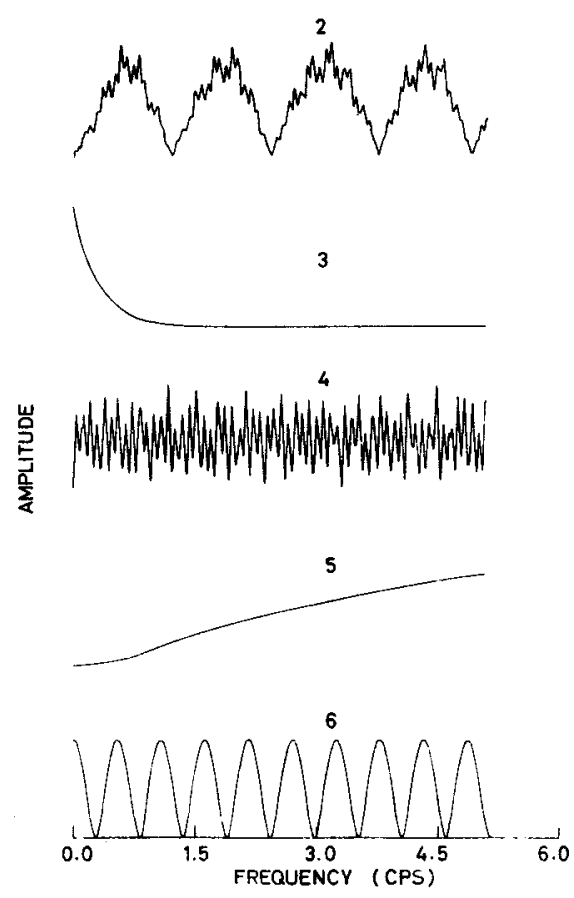
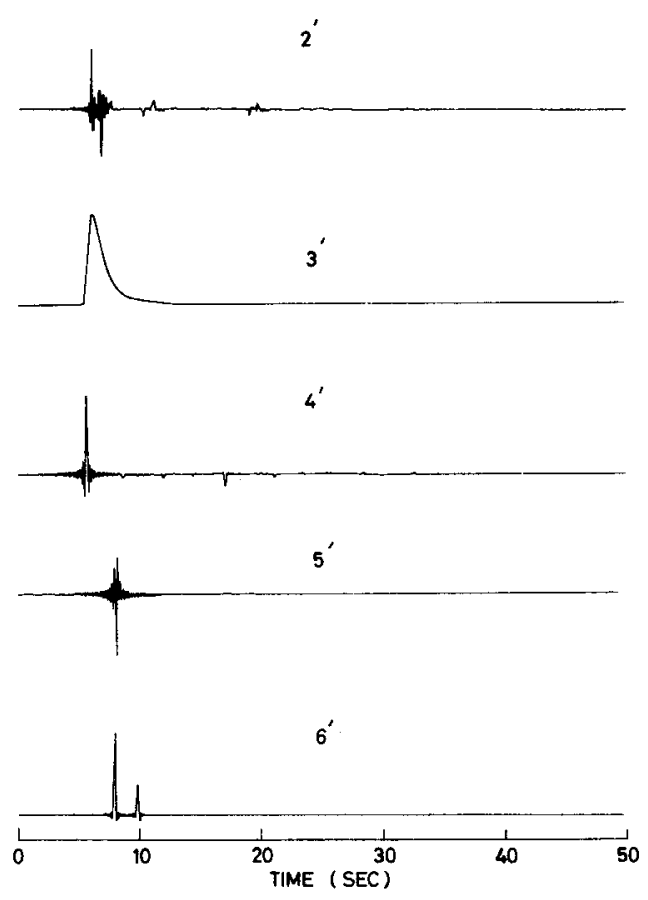

Figure 7. show's the amplitude spectra and impulse responses of transfer functions that were held constant while computing the variations in the amplitude spectrum and waveforms for Cannikin as signal propagates from source to GBA. Symbols same as in figure 1.

Traces ${ }^{\prime} 1$ in figure 10 show that the amplitude of the second trough of observed seismograms is more as compared to first trough, whereas the reverse is the case in synthesized seismograms. While studying the spectral amplitude ratios of $P$ waves generated by these explosions, it was reported by Frasier (1972), King et al (1972. 1974) that in source region the inferred overburden $P$ wave velocity is less as compared to its value obtained from on-site measurements. The crustal model in source region (table 2a) was modified in such a fashion that the overburden $P$ wave velocity is that inferred by King $e l a /$ (1972) and $P$ wave seismograms were recomputed at GBA, EKA, WRA and YKA seismic array stations for Longshot explosion. Like observed $P$ seismograms, recomputed seismograms show that the amplitude of the second trough is more as compared to the first trough. This result shows that the depth determined from $P$ wave seismograms will be different than actual depth. This result is very significant. 

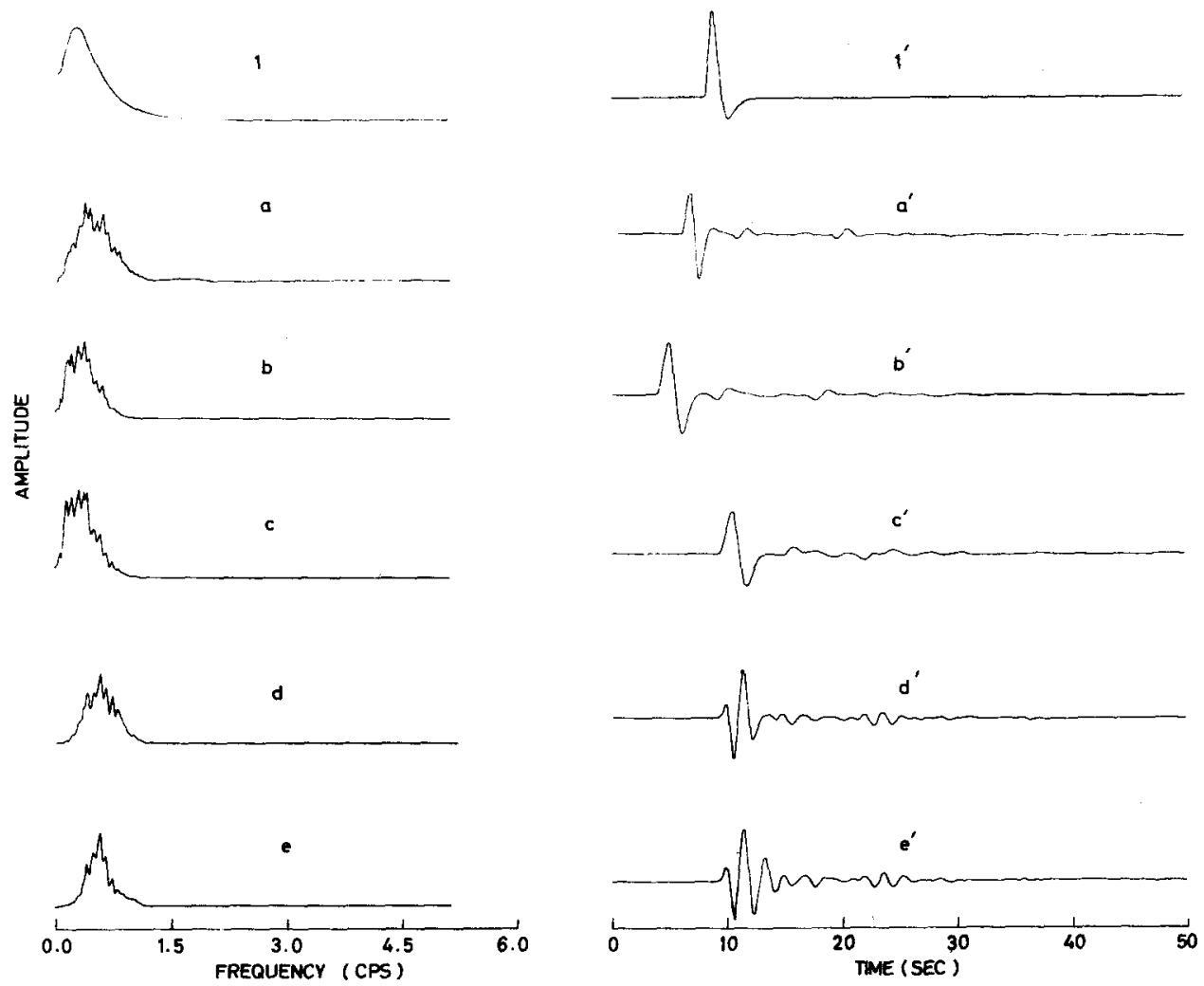

Figure 8. Amplitude spectrum and waveform for Cannikin as signal propagates from source to GBA. Source model is that of Haskell. Symbols same as in figure 2.

\section{Conclusions}

Step-by-step variations in the amplitude spectra and waveforms of $P$ wave signal as it propagates from source region at Amchitka to receiver at GBA, are presented for Longshot, Milrow and Cannikin underground explosions. It is shown that pulse shapes of $\boldsymbol{P}$ waves predicted both by Haskell and Seggern source models are almost equivalent for all practical purposes. The period as well as amplitude of computed seismograms increase with increase in yield. Computed and observed $P$ wave seismograms for Longshot at various seismic array stations of UKAEA were compared. It is noticed that many features of observed seismograms are reproduced in computed seismograms. Seismograms were also computed using the value of overburden $P$ wave velocity given by King et al (1974). It is interesting that the recomputed seismograms 

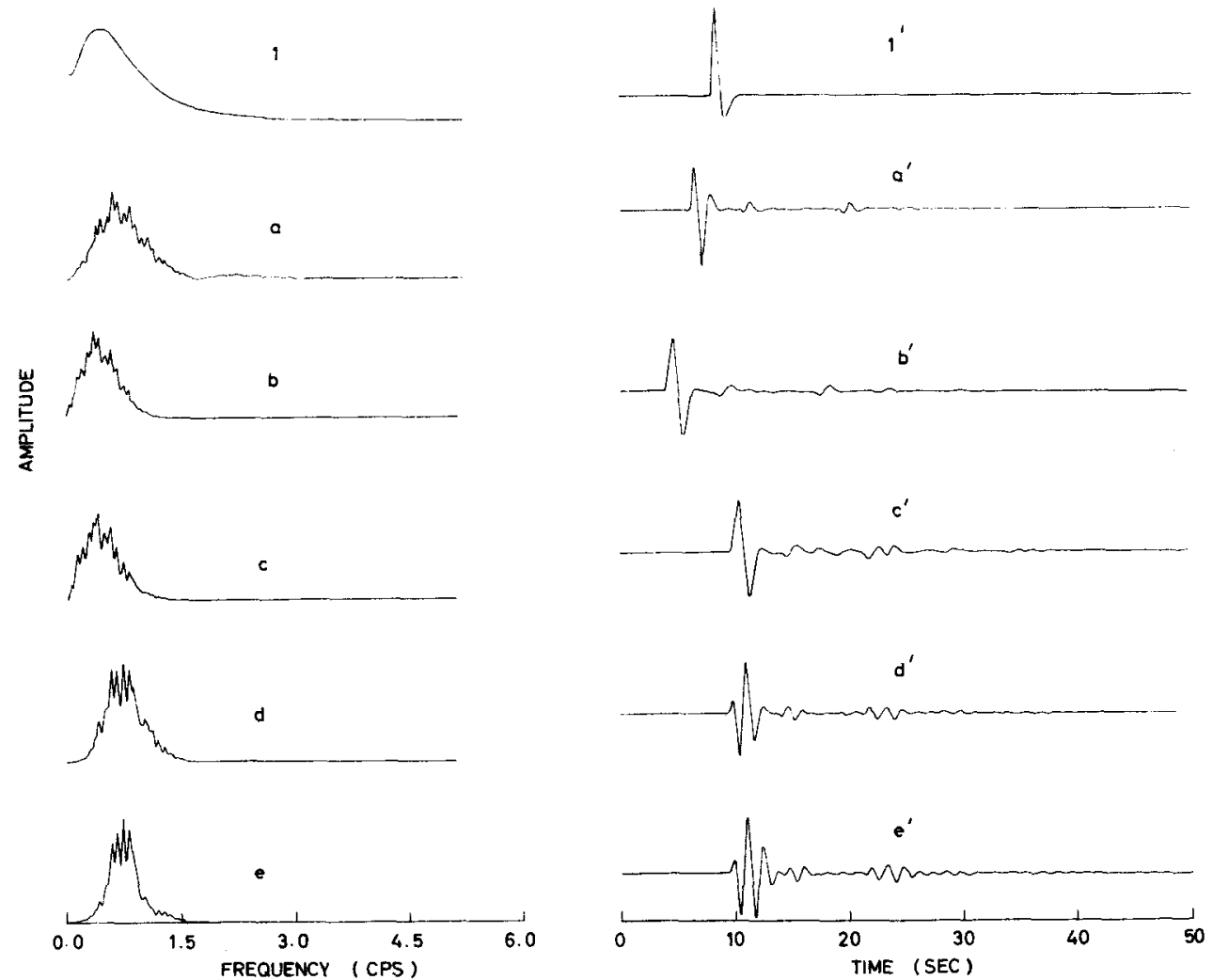

Figure 9. Amplitude spectrum and waveform for Cannikin as signal propagates from source to GBA. Source model is that of Seggern. Symbols same as in figure 2.

compare better with observed seismograms. This result supports the conclusion that overburden $P$ wave velocity inferred from seismograms is less as compared to its value obtained from on-site measurements. The results obtained show that the source function, the source crust transfer function, the mantle transfer function and the spalling function are the most important factors that influence shaping of spectra and seismograms. This study is also useful in distinguishing between underground explosions and earthquakes. 


\section{LONGSHOT EXPLOSION}

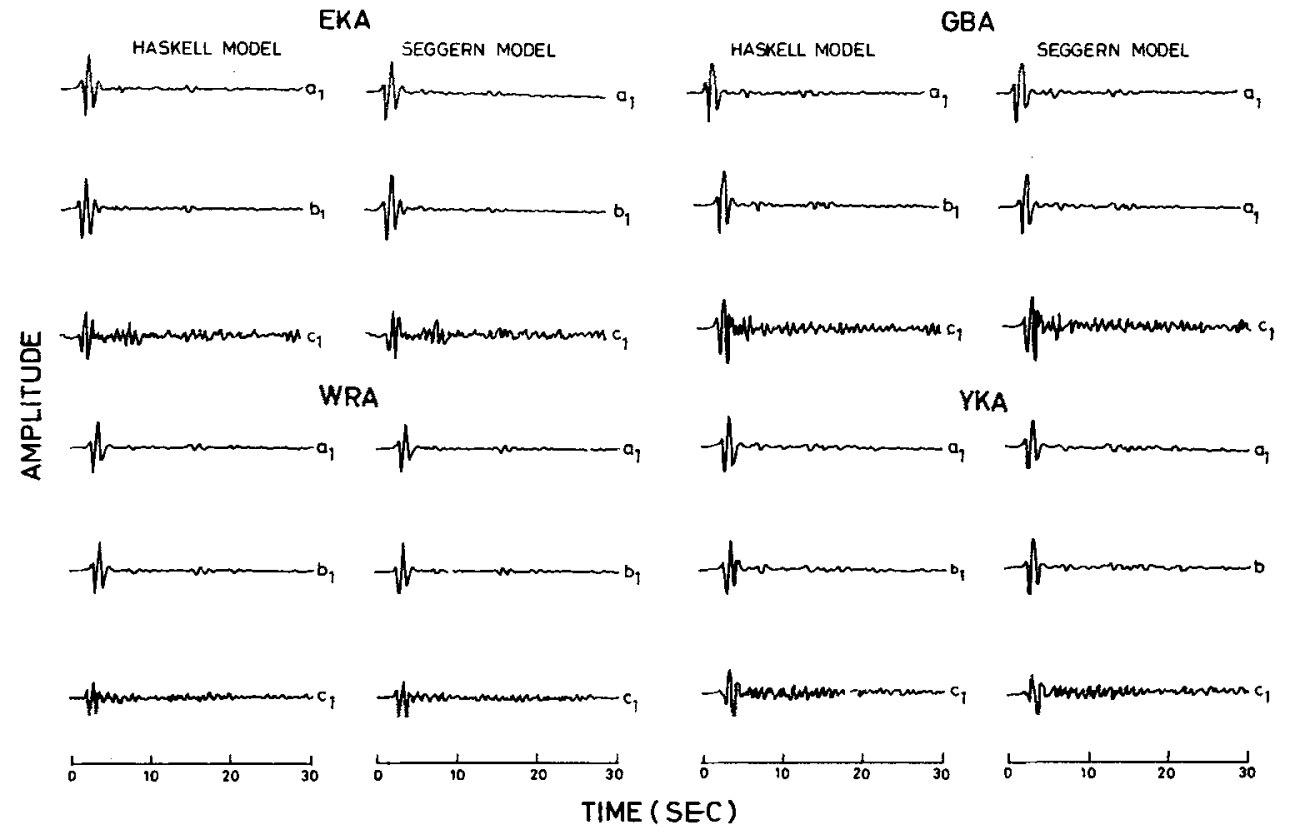

Figure 10. Comparison of synthesized and observed $P$ wave seismograms at GBA. EKA. WRA and YKA for source models of Haskell and Seggern. Computed $P$ wave seismograms w ithout taking into account the effect of spalling are shown by traces $a_{1}$. Composite synthesiged seismograms are shown by traces $h_{1}$ whereas traces c' show observed seismograms.

\section{Acknowledgements}

The author is thankful to Dr G S Murty and Mr G J Nair for useful discussions during this investigation.

\section{References}

Aki K. Bouchon M and Reasenberg P 1974 Bull. Seismol. Soc. Am. 64131

Arora S K 1977 Crustal structure near Gauribidanur in Southern India from Gauribidanur data of local earthquakes, rock-hursts and explosions, Ph.D. thesis. University of Bombay

Bakun W H and Johnson L R 1971 Geophys. J. R. Astron. Soc. 22139

Banghar A R 1970 Earthquake Notes 4145

Banghar A R 1980a Synthetic seismograms-I. Transfer functions for synthesis of $P$ wave seismograms from explosive sources and their parametric study. BARC Report I-617

Banghar A R 1980b Synthetic seismograms - II. Synthesis of amplitude spectra and seismograms from underground nuclear explosions. BARC Report 1085

Banghar A R 1981 Mechanisms of earthquakes and sythesis of $P$ wave seismograms from explosions and earthquakes, Ph.D. thesis. University of Bombay 
Banghar A R 1982 Phys. Earth Planet. Interior. (submitted)

Barr K G 1971 J. Geophys. Res. 761929

Ben-Menahem A 1967 in Current status and future prognosis for understanding the source mechanism of shallow seismic events in the 3-5 magnitude range. Proc. Vesiac Conf., Willow Run Lab., University of Michigan. USA p. 85

Ben-Menahem A and Toksoz. M N 1962 J. Geophis. Res. 685207

Buchbinder G G R 1968 Bull. Seismol. Soc. Am. 581797

Burdick L J and Helmberger D V 1979 Bull. Seismol. Soc. Am. 69957

Carpenter E W 1966 Proc. R. Soc. (London) A290 396

Carpenter E. W and Flinn F. A 1965 Nature (London) 207745

Carpenter E W and Thirlaway H I S 1966 Seismic signal anomalies. travel times. amplitude and pulse shapes, Proc. Vesiac Special Suldy Conf.. Report 4410-99-X. Willow Run Lab.. University of Michigan. USA

Cleary J 1974 Tecronophysics 20241

Douglas A. Hudson J A and Blamey C 1972 Geophis. J. R. Astron. Soc. 28385

Eisler J D and Chilton F $1964 J$. Geophys. Res. 695285

Engdahl E R and Tarr A C 1970 Aleutian seismicity: Milrow seismic effects. CGS-746-102, US Coast and Geodetic Survey. Environ. Sci. Serv. Admin., Boulder. Colo. USA

Frasier C W 1972 Geophys. J. R. Astron. Soc. 3199

Fuchs K 1966 Bull. Seismol. Soc. Am. 5675

Futterman W I 1962 J. Geophys. Res. 675279

Hasegawa H S 1971 Geophys. J. R. Astron. Soc. 24365

Hasegawa H S 1972 J. Geophis. Res. 773081

Hasegawa H S 1973 Bull. Seismol. Soc'. Am. 631201

Haskell N A 1953 Bull. Seismol. Soc. Am. 43120

Haskell N A $1962 J$. Geophis. Res. 674751

Haskell N A $1967 J$. Geophys. Res. 722583

Helmberger D V and Harkrider D G 1972 Geophis. J. R. Astron. Soc. 3145

Holzer F 1966 Proc. R. Soc: (London) A290 408

King C. Bakun W H and Murdock J N 1972 J. R. Astron. Soc. 3127

King C. Abe Zena A M and Murdock J N 1974 J. Geophys. Res. 79712

Kogeus K 1968 Bull. Seismol. Soc. Ant. 58663

l.iebermann R C and Pomeroy P W 1969 J. Geophys. Res. 741575

liebermann R C and Pomeroy P W 1970 Bull. Seismol. Soc. Am. 60879

McFvilly T V and Peppin W A 1972 Geophys. J. R. Astron. Soc. 3167

Molnar P 1971 Geophis. J. R. Astron. Soc. 23273

Mowat W M H and Burch R F 1974 Handbook of stations which provide seismograms to the Blacknest Seismology Centre, AWRF. Aldermaston, Berks, UK

Muller G 1973 Bull. Seismol. Six. Am. 63847

Murphy J R 1977 Bull. Seismol. Soc. Am. 67135

Nair G J 1977 Some seismic results of the Rajasthan explosion of 18 May 1974. AG-224. AWRE. Aldermaston. Berks. UK

Orphal D I. Spiker C T. West I. R and Wronski M D 1970 Analysis of seismic data: Milrow Event. NVO 1163-209. Environ. Res. Corpn.. Alexandria, Va

Parks R 1967 Seismic refraction network in the studly of earth's crust. Ph. D. thesis. University of Edinburgh Rinchart R A 1960 Fing. Mining J. 16198

Seggern V D and l.ambert D G $1970 \mathrm{~J}$. Geophys. Res. 757382

Seggern V D and I.ambert D G 1972 Analysis of teleseismic data from nuclear explosion Milrow. Seismic Data l.ab. Report 258. AD 743 072. Teledyne Geotech

Seggern V D and Blandford R 1972 Geophis. J. R. Asurm. 318.

Springer D I. 1974 Bull. Seismol. Soc. Am. 64581

Tsai Y and Aki K 1970 J. Geophys. Res. 755729

Tsai $\mathrm{Y}$ and Aki K 1971 J. Geophis. Res. 763940

Werth G C and Hurst R F $1963 \mathrm{~J}$. Geophys. Res. 681463

Wyss M. Hanks T C and Liebermann R C 1971 J. Geophrs. Res. 762716 